cent). Finally, we observed no treatment failures for chlamydial infection among 57 men who reported not having had sexual intercourse during follow-up.
Matthew R. Golden, M.D., M.P.H.

William L.H. Whittington, A.B.

King K. Holmes, M.D., Ph.D.

University of Washington

Seattle, WA 98104

\title{
Angiotensin II Type 1-Receptor Activating Antibodies in Renal-Allograft Rejection
}

TO THE EDITOR: Dragun et al. (Feb. 10 issue) ${ }^{1}$ provide provocative data on the role of agonistic angiotensin II type $1\left(\mathrm{AT}_{1}\right)$-receptor antibodies in patients with steroid-refractory renal-allograft rejection. We were surprised by the high incidence of biopsy-proved acute rejection among their patients (43 percent), which contrasts with the 15 percent previously reported with a similar immunosuppressive protocol.2,3 In addition, 16 of the 33 patients with steroid-refractory rejection in the study by Dragun et al. appeared to have malignant hypertension. The median blood pressure was 153/80 $\mathrm{mm} \mathrm{Hg}$ in the 10 most recent patients with steroidrefractory rejection in our medical center, only 1 of whom had signs of hypertensive encephalopathy. Finally, information about the original renal disease of the patients is lacking - a relevant point because the $\mathrm{AT}_{1}$-receptor antibodies were probably preexistent. We recently observed that patients who had the hemolytic-uremic syndrome are prone to have vascular rejection. ${ }^{4}$ Moreover, $\mathrm{AT}_{1}$-receptor antibodies have been described in other microangiopathic conditions, such as preeclampsia and malignant hypertension. ${ }^{5}$ We propose that the combination of vascular rejection and $\mathrm{AT}_{1}$-receptor antibodies occurs particularly in patients who have the hemolytic-uremic syndrome or malignant hypertension as their original renal disease.

Luuk Hilbrands, M.D.

Andries Hoitsma, M.D.

Jack Wetzels, M.D.

Radboud University Nijmegen

6500 HB Nijmegen, the Netherlands

l.hilbrands@nier.umcn.nl

1. Dragun D, Müller DN, Bräsen JH, et al. Angiotensin II type Ireceptor activating antibodies in renal-allograft rejection. $\mathrm{N}$ Engl J Med 2005;352:558-69.

2. Lawen JG, Davies EA, Mourad G, et al. Randomized doubleblind study of immunoprophylaxis with basiliximab, a chimeric anti-interleukin-2 receptor monoclonal antibody, in combination with mycophenolate mofetil-containing triple therapy in renal transplantation. Transplantation 2003;75:37-43.
3. ter Meulen CG, van Riemsdijk I, Hene RJ, et al. Steroid-withdrawal at 3 days after renal transplantation with anti-IL-2 receptor alpha therapy: a prospective, randomized, multicenter study. Am J Transplant 2004;4:803-10.

4. Artz MA, Steenbergen EJ, Hoitsma AJ, Monnens LA, Wetzels JF. Renal transplantation in patients with hemolytic uremic syndrome: high rate of recurrence and increased incidence of acute rejections. Transplantation 2003;76:821-6.

5. Fu ML, Herlitz H, Schulze W, et al. Autoantibodies against the angiotensin receptor (AT1) in patients with hypertension. J Hypertens 2000;18:945-53.

TO THE EDITOR: The incidence of severe hypertension after renal transplantation is primarily related to the presence of malignant hypertension in the pretransplantation period. ${ }^{1}$ The original disease influences the outcome of kidney transplantation; in particular, recipients with malignant hypertension have poorer graft survival. ${ }^{2}$ No information, however, is provided in the article by Dragun et al. about the original cause of end-stage renal disease, posttransplantation antihypertensive medication, or mean blood pressure before and after transplantation. Such data would be important, since hypertension was the sole clinical factor discriminating between the two groups. It was unclear in the paper by Dragun et al. whether this entity represents a subtype of acute rejection or recurrent disease. Preformed $\mathrm{AT}_{1}$-receptor antibodies must have been present at the time of transplantation in at least some patients in whom clinical events occurred within days after transplantation. The failure to identify low levels of anti-HLA antibodies with sensitive solid-phase assays $\mathrm{s}^{3,4}$ as well as levels of antibodies that are non-donor-specific ${ }^{5}$ may have affected both the accuracy of the subsequent analysis and the conclusions, which were dependent on the stratification of patients according to these criteria.

M. Javeed Ansari, M.B., B.S., M.R.C.P.

Kathryn Tinckam, M.D., F.R.C.P.C.

Anil Chandraker, M.B., F.R.C.P.

Brigham and Women's Hospital

Boston, MA 02115 
1. Ianhez LE, Sabbaga E. Blood pressure behaviour in patients with malignant hypertension submitted to kidney transplantation. Nephron 1978;22:217-25.

2. Oriol R, Le Pendu J, Chun C. Influence of the original disease, race, and center on the outcome of kidney transplantation. Transplantation 1982;33:22-6.

3. Terasaki PI, Ozawa M. Predicting kidney graft failure by HLA antibodies: a prospective trial. Am J Transplant 2004;4:438-43.

4. Bittencourt MC, Rebibou JM, Saint-Hillier Y, et al. Impaired renal graft survival after a positive B-cell flow-cytometry crossmatch. Nephrol Dial Transplant 1998;13:2059-64.

5. Gebel HM, Harris SB, Zibari G, Bray RA. Conundrums with FlowPRA beads. Clin Transplant 2002;16:Suppl 7:24.

THE AUTHORS REPLY: Our first patient, who did not have hypertension, was the recipient of a "fullhouse" matched transplant with no panel reactivity. Severe vascular rejection, malignant hypertension, and seizures developed after transplantation. We were struck by the fact that she had had preeclampsia nearly two decades earlier. We detected $\mathrm{AT}_{1}$-receptor-activating autoantibodies in this patient, treated her blood pressure, and rescued the transplant with plasmapheresis and an $\mathrm{AT}_{1}$-receptor blocker. We next screened serum samples from all patients with steroid-refractory rejection over a four-year period for anti-HLA reactivity, donor specificity, and $\mathrm{AT}_{1}$-receptor antibodies. We minimized selection bias by testing all serum samples for all variables. We reported reactivity against HLA antigens in both groups of patients and also indicated that determinations of $\mathrm{AT}_{1}$-receptor antibodies were performed. Although a few patients showed moderate HLA reactivity, these antibodies lacked donor specificity, as confirmed by the results of an HLA-antigen-specific enzyme-linked immunosorbent assay. ${ }^{1} \mathrm{C} 4 \mathrm{~d}$-negative biopsy specimens argued against intragraft adsorption of donor-specific antibodies. $^{2}$

End-stage renal disease was attributed to small, contracted kidneys in eight patients, in whom no biopsy was performed before transplantation. Other causes of end-stage renal disease were autosomal dominant polycystic kidney disease, juvenile nephronophthisis, focal segmental glomerulosclerosis, chronic tubulointerstitial nephritis, and, in just one patient, well-documented hypertensive nephroscle- rosis. None had end-stage renal disease due to the hemolytic-uremic syndrome. We believe that specific causes of end-stage renal disease and the presence or absence of hypertension before transplantation were not necessarily relevant, although we cannot prove that assumption with certainty. The hemolytic-uremic syndrome clearly warrants further study.

We documented 119 rejection episodes in 83 of 279 patients during a mean $( \pm S D)$ of $26.2 \pm 15$ months of follow-up. Seventy-three patients had a first rejection within six months after transplantation, for a rejection rate of 26.2 percent, which is similar to the rates in the reports cited by the correspondents. ${ }^{3}$ Most of the patients (13 of 16) did not have hypertension before vascular rejection occurred. This finding suggests that the post-transplantation hypertension was secondary to rejection. $\mathrm{AT}_{1}$-receptor antibodies transferred to animals that had received transplants as part of our study induced first rejection and then hypertension. We suggest that the $\mathrm{AT}_{1}$-receptor antibodies mediated hypertension by augmenting a local intrarenal renin-angiotensin system by way of activation of $\mathrm{AT}_{1}$ receptors in a kidney with vascular rejection. ${ }^{4}$ However, our study did not test the relevance of hypertension in antibody-mediated rejection - an issue that warrants further investigation.

\section{Duska Dragun, M.D.}

Lutz Fritsche, M.D.

Charité University Hospital

10117 Berlin, Germany

duska.dragun@charite.de

Friedrich C. Luft, M.D.

Franz Volhard Clinic

13125 Berlin, Germany

1. Gebel HM, Bray RA, Nickerson P. Pre-transplant assessment of donor-reactive, HLA-specific antibodies in renal transplantation: contraindication vs. risk. Am J Transplant 2003;3:1488-500.

2. Terasaki P. Humoral theory of transplantation. Am J Transplant 2003;3:665-73.

3. ter Meulen CG, van Riemsdijk I, Hene RJ, et al. Steroid-withdrawal at 3 days after renal transplantation with anti-IL-2 receptor alpha therapy: a prospective, randomized, multicenter study. Am J Transplant 2004;4:803-10.

4. Kobori H, Prieto-Carrasquero MC, Ozawa Y, Navar LG. $\mathrm{AT}_{1}$ receptor mediated augmentation of intrarenal angiotensinogen in angiotensin II-dependent hypertension. Hypertension 2004;43:1126-32. 